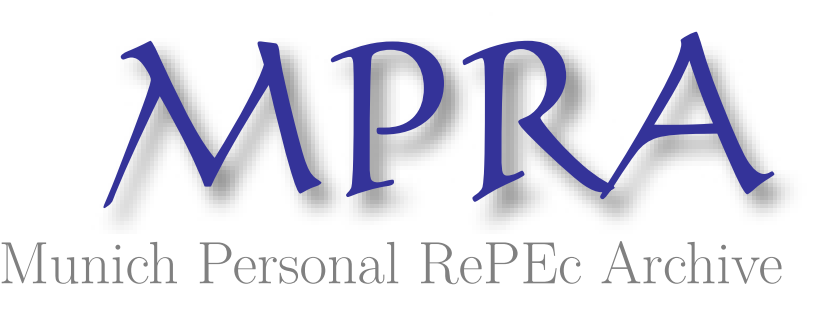

\title{
Optimal Monetary Policy and Downward Nominal Wage Rigidity in Frictional Labor Markets
}

\author{
Abo-Zaid, Salem \\ University of Maryland, College Park
}

24 September 2009

Online at https://mpra.ub.uni-muenchen.de/17489/

MPRA Paper No. 17489, posted 28 Sep 2009 08:46 UTC 


\title{
Optimal Monetary Policy and Downward Nominal Wage Rigidity in Frictional Labor Markets
}

First Draft- February 2009

This Draft- September 2009

Salem Abo-Zaid

\begin{abstract}
Recent empirical evidence suggests that nominal wages in the U.S. are downwardly rigid. This paper studies optimal monetary policy in a labor search and matching framework under the presence of Downward Nominal Wage Rigidity (DNWR). The study shows that when nominal wages are downwardly rigid, optimal monetary policy targets a positive inflation rate; the annual long-run inflation rate is around 2 percent. Positive inflation in this environment "greases the wheels" of the labor market by facilitating real wage adjustments, and hence it eases job creation and prevents excessive increase in unemployment. In addition, there is an asymmetry in the response of the economy to positive and negative productivity shocks, particularly those of large sizes. Finally, the optimal long-run inflation rate predicted by this study is considerably higher than in otherwise neoclassical labor markets, suggesting that the nature of the labor market in which DNWR is studied can matter for policy recommendations.
\end{abstract}




\section{Introduction}

This paper studies optimal monetary policy under the presence of Downward Nominal Wage Rigidity (DNWR) within a labor search and matching model. ${ }^{1}$ The main finding of this study is that when nominal wages are more downwardly than upwardly rigid, optimal monetary policy sets a strictly positive inflation rate; the optimal annual long run inflation rate is about 2.0 percent. The study also points to a considerable asymmetry in the response of the economy to adverse and positive shocks, in particular following shocks of big sizes. The asymmetry is particularly significant in the case of price inflation.

The main reason for the significant (and positive) deviation from zero inflation rate is to allow for real wage adjustments and thus to both ease job creation and limit the increase in unemployment following negative shocks. Indeed, in a model where the monetary authority commits to a zero inflation rate at all dates and states, downward rigidity in nominal wages combined with fully stable prices limits the size of the drop in real wages significantly. In this case, unemployment increases and job creation falls far beyond their levels under a moderately positive inflation target.

The study is motivated by several recent empirical studies indicating DNWR. One of the most notable recent evidence on DNWR is the comprehensive work of the International Wage Flexibility Project (IWFP), reviewed in Dickens et al.(2007a, 2007b). Their findings indicate asymmetry in the distribution of nominal wage changes in 16 OECD countries, with the U.S. being among the countries with very high degrees of DNWR. Gottschalk (2005) shows that after correcting for measurement errors that typically appear in wages reported in surveys, only about $5 \%$ of workers experienced wage cuts during a course of a year while working for the same employer. Card and Hyslop (1997) show a spike at zero in the distribution of nominal wage changes, indicating DNWR. The size of this spike is highly correlated with inflation; it significantly increases in the mid 1980's when inflation rates fell relative to the 1970's. In addition, their analysis reveals that, on average, real wages would have been lower by around $1 \%$ per year in the mid 1980's had nominal wages not been downwardly rigid. Using large financial corporation wage

${ }^{1}$ DNWR does not only mean that wage increases are more likely than wage cuts, but also that the distributions of wage changes are not symmetric. Nominal wages tend to increase in good times but they do not tend to fall proportionally in bad times, thus generating an asymmetric distribution of wage changes. Note that the fact that wage increases are more common than wage cuts by itself is insufficient evidence for the presence of DNWR: a preponderance wage increases may reflect long-term productivity growth or steady state (positive) inflation. 
and salary data, Altonji and Devereux (2000) find that only $0.5 \%$ of salaried workers had wage cuts and $2.5 \%$ of hourly workers had wage reductions. ${ }^{2}$

The idea that positive inflation may be needed to grease the wheels of the labor market dates back at least to Tobin's 1971 American Economic Association presidential address (Tobin, 1972). Following negative shocks that call for a fall in the real wage, Tobin (1972) suggested that setting a positive inflation rate on one hand and stabilizing nominal wages on the other would facilitate real wage adjustment in the presence of DNWR. Tobin's idea has gained more attention in recent years for two main reasons. First, inflation rates have become very low in the last two decades. Clearly, DNWR is more relevant in low inflation environments and during periods of recessions. Second, central banks around the world do in fact target, either explicitly or implicitly, positive inflation rates. DNWR may be a reason for the precautionary motive behind positive inflation: since the timing of (negative) shocks is not fully predicted, the monetary authority keeps the inflation rate positive on average in order to "insure" against these events once they occur.

The study allows for staggered prices setting, downwardly rigid nominal wages, and search and matching frictions in the labor market; the latter being consistent with positive unemployment in equilibrium. To model DNWR, I follow Kim and Ruge-Murcia (2009) and Fahr and Smets (2008) and use the Linex wage adjustment cost function. This function delivers higher costs in case of wage cuts relative to wage increases. To see the significance of this setup, consider the response of an economy to an adverse productivity shock. If inflation is high, then downward rigidity in nominal wages cannot prevent real wage drops, and hence inflation mitigates the potential increase in unemployment. In case of low inflation rates, however, DNWR may translate into Downward Real Wage Rigidity (DRWR). In this case, if the monetary authority seeks to keeps prices around full stability (due to the presence of a direct cost of adjusting prices), downward rigidity in real wages implies higher unemployment than in the absence of DNWR. If the monetary authority instead chooses to stabilize employment, it inflates in order to achieve the desired cut in real wages. That is, the inflation rate needed 'to grease the wheels' of the economy is higher than it would be if nominal wages have not been downwardly rigid. In short, the presence of labor market frictions may magnify the need for grease inflation if the planner is trying to keep unemployment low, or it may create excessive unemployment when attempting to keep prices close to full stability.

${ }^{2}$ DNWR has been also found in the data of other countries: Kuroda and Yamamoto (2003) report DNWR in Japan; Fehr and Goette (2005) study Switzerland and Castellanous et al (2004) examine Mexico. 
The recent work by Kim and Ruge-Murcia (2009) studies the implications of DNWR for monetary policy assuming neoclassical labor markets shows that the optimal (annual) grease inflation in the U.S. is positive (around 0.4 percent). Note however that, unlike the current study, monetary policy in their model is implemented by a Taylor-type rule. In an earlier version of their paper (Kim and Ruge-Murcia, 2007), the monetary authority chooses allocations to maximize households' welfare, but without assuming any Taylor-type rule. In that case, the optimal (annual) grease inflation is found to be 1.2 percent. In this regard, the optimal long run inflation rate found in my work is significantly higher than those reported in either of their versions. Since the discussion is over the long run inflation rate, these differences are economically significant.

The remainder of this paper proceeds as follows. Section 2 outlines the search and matching model economy with the proposed wage adjustment cost. Section 3 describes the calibration methodology and the parameterization of the model. Section 4 discusses optimal monetary policy under DNWR and presents the optimal grease inflation rate. Impulse Response functions following productivity shocks are presented in section 5. Section 6 examines the performance of two extremes policies relative to optimal policy- full price stability and full employment stability. Section 7 concludes. 


\section{The Model Economy}

This section describes the model I use to study optimal monetary policy under the presence of DNWR within a search and matching framework. The section first outlines the household's problem and then moves to describe firms. As in recent studies, the model embeds the search and matching framework of Pissarides (2000), which has become the main framework within which optimal monetary policy is studied in the presence of labor market frictions. ${ }^{3}$ The model below will allow for variations in total hours along both the extensive and the intensive margin. Finally, the section is closed by presenting the private sector equilibrium and the optimal monetary policy problem.

\subsection{Households}

The economy is populated by a representative household which consists of family members of measure one. At each date $t$ a household member can be in either of two states: employed or unemployed and searching for a job. Employed individuals are of measure $n_{t}$ and the unemployed are of measure $u_{t}$, where $u_{t}=1-n_{t}$, as conventional in the literature.

Following the assumptions of consumption insurance in Merz (1995) and Andolfatto (1996), all family members in this household have the same consumption. The disutility of work is assumed to be the same for all employed individuals and the value of non-work is the same for all unemployed individuals. Given these assumptions, the household's problem is to maximize lifetime utility given by

$$
\operatorname{Max} E_{0} \sum_{t=0}^{\infty} \beta^{t}\left[u\left(c_{t}\right)-n_{t} v\left(h_{t}\right)\right]
$$

subject to the sequence of budget constraints of the form

$$
c_{t}+\frac{B_{t}}{P_{t}}=\frac{n_{t} h_{t} W_{t}}{P_{t}}+\left(1-n_{t}\right) b+\frac{R_{t-1} B_{t-1}}{P_{t}}+\frac{T_{t}}{P_{t}}+\frac{\Theta_{t}}{P_{t}}
$$

\footnotetext{
${ }^{3}$ Note that my model assumes no idiosyncratic shocks, unlike for example, Mortensen and Pissarides (1994).
} 
where $c_{t}$ denotes consumption, $b$ stands for unemployment benefits, $v\left(h_{t}\right)$ denotes disutility from work, $B_{t}$ denotes nominal bonds, $R_{t}$ is the nominal gross interest rate on bonds, $P_{t}$ is the aggregate price level, $T_{t}$ are net transfers and $\Theta_{t}$ stands for profits from firms.

Household's choices of consumption and bond holdings yield the following first order conditions (with $\lambda_{t}$ denoting the Lagrange multiplier of the budget constraint)

$$
u_{c t}=\lambda_{t}
$$

$$
\lambda_{t}=\beta R_{t} E_{t}\left(\frac{\lambda_{t+1}}{\pi_{t+1}}\right)
$$

These two first order conditions combined give the following Euler equation for consumption

$$
u_{c t}=\beta R_{t} E_{t}\left(\frac{u_{c t+1}}{\pi_{t+1}}\right)
$$

in which $\left(\pi_{t+1}=P_{t+1} / P_{t}\right)$ denotes the gross price inflation rate.

\subsection{The production Sector}

Following Walsh (2005), Gertler, Sala and Trigari (2008) and Thomas (2008), I assume two types of firms- intermediate (wholesale) firms and retailers. Intermediate Firms produce a homogenous good in a competitive market using labor as the only input. Hiring workers in this sector is subject to search and matching costs. Each period firms post vacancies and they meet unemployed workers searching for jobs. Wages are determined in a Nash Bargaining process between workers and firms as will be outlined later. Intermediate firms sell their output to monopolistically competitive firms who package them into final goods using a one-to-one constant return to scale technology. The main reason for separating intermediate firms from retailers is to keep the bargaining and job creation problems tractable; the search and matching 
frictions in the labor market arise at the intermediate-firm level, while price rigidities arise at the retail level. $^{4}$

\subsubsection{Firms in the Intermediate Competitive Sector}

Firms in this market use labor as their only input to produce a homogenous good. The firm faces an asymmetric wage adjustment cost function that involves a higher cost in case of a nominal wage cut compared to a nominal wage increase. ${ }^{5}$ In particular, following Kim and Ruge-Murcia (2009), the real wage adjustment cost is given by the following Linex function:

$\Phi_{j t}^{W}=\frac{\phi}{\psi^{2}}\left(\exp \left[-\psi\left(\frac{W_{j t}}{W_{j t-1}}-1\right)\right]+\psi\left(\frac{W_{j t}}{W_{j t-1}}-1\right)-1\right)$

Note that for any positive value of the parameter $\psi$, the cost of cutting nominal wages by a specific magnitude is higher than the cost of increasing wages by the same magnitude. Also, as $\psi$ approaches zero, this function approaches the quadratic adjustment cost and hence enables comparison with the symmetric adjustment function case. Naturally, this parameter is of central importance in what follows since it is basically what drives the wedge between the symmetric and asymmetric adjustment cost functions.

Moreover, each firm produces its output using to the following production function

$y_{j t}=z_{t} n_{j t} f\left(h_{j t}\right)$

with $z$ denoting aggregate productivity. Aggregating over firms gives aggregate Output: $y_{t}=z_{t} n_{t} f\left(h_{t}\right)$.

\footnotetext{
${ }^{4}$ See Gertler, Sala and Trigari (2008) for further discussion.

${ }^{5}$ The assumption that firms pay the adjustment costs of wages is without loss of generality. In a model where workers unilateraly set their wages, they will naturally pay the wage adjustment cost. In this model however, the wage rate is determined through bargaining between firms and workers. Hence, households do not have all the bargaining power and they therefore are not wage setters in the typical manner. In this case, it is less clear who should pay the cost of adjusting wages. I assume that firms entail these costs without loss of generality. Note that this assumption has no effect on the economy-wide resource constraint.
} 
Hiring workers in the intermediate sector is subject to search and matching costs. Firms post vacancies and they meet unemployed workers searching for jobs. Posting a vacancy $v$ entails a cost of $\gamma$ for a firm. Matches between vacant jobs and unemployed individuals are governed by a constants return to scale matching function of the form

$$
m\left(v_{t}, u_{t}\right)=\sigma_{m} u_{t}^{\zeta} v_{t}^{1-\zeta}
$$

where $\sigma_{m}$ is a scaling parameter that reflects the efficiency of the matching process. Labor market tightness is measured as

$\theta_{t}=\frac{v_{t}}{u_{t}}$

The probability of the firm to fill a job (i.e. the job filling rate) is given by

$q_{t}=q\left(\theta_{t}\right)=\frac{m\left(v_{t}, u_{t}\right)}{v_{t}}=\sigma_{m} \theta_{t}^{-\zeta}$

which is decreasing in labor market tightness. Intuitively, the higher the ratio of vacancies to unemployment, the lower the probability for a specific vacancy to be filled. In contrast, the job finding rate for unemployed workers increases in tighter labor markets. Formally, the job finding rate is

$p_{t}=p\left(\theta_{t}\right)=\frac{m\left(v_{t}, u_{t}\right)}{u_{t}}=\sigma_{m} \theta_{t}^{1-\zeta}$

Finally, following Arseneau and Chugh (2008) and Krause and Lubik (2007) among others, employment in each firm evolve according the following law of motion:

$n_{j t+1}=(1-\rho)\left(n_{j t}+m\left(v_{j t}, u_{t}\right)\right)$

which, using the expression for the job-filling rate and denoting the separation rate form a match by $\rho$ can also be written as

$n_{j t+1}=(1-\rho)\left(n_{j t}+v_{j t} q\left(\theta_{t}\right)\right)$ 
I assume in this formulation that a job formed at time $t$ start to produce at time $t+1$ given it survived exogenous separation. An alternative formulation is not to allow for separation of a match formed at time $t$ (as for example in Walsh, 2005).

Given the competitive price $\tilde{P}_{t}$, the firm's problem is to choose vacancies and employment for next period to maximize its expected discounted stream of profits subject to the sequence of laws of motion of employment:

$\operatorname{MaxE}_{0} \sum_{t=0}^{\infty} \beta^{t}\left\{\frac{\lambda_{t}}{\lambda_{0} P_{t}}\left[\widetilde{P}_{t} n_{j t} z_{t} f\left(h_{j t}\right)-n_{j t} W_{j t} h_{j t}-\gamma P_{t} v_{j t}-\frac{\phi}{\psi^{2}}\left(\exp \left[-\psi\left(\frac{W_{j t}}{W_{j t-1}}-1\right)\right]+\psi\left(\frac{W_{j t}}{W_{j t-1}}-1\right)-1\right) P_{t} n_{j t}\right]\right\}$

s.t.

$n_{j t+1}=(1-\rho)\left(n_{j t}+v_{j t} q\left(\theta_{t}\right)\right)$

Note that I assume that households own the firms and hence firms discount next period's profits by the stochastic discount factor of households (i.e. $\beta \frac{\lambda_{t}}{\lambda_{0} P_{t}}$ ). Letting $\mu_{t}$ be the Lagrange multiplier associated with the employment law of motion and imposing symmetry across firms, the first order conditions with respect to $n_{j t+1}$ and $v_{j t}$ read as follows:

$\mu_{t} \frac{\lambda_{t}}{P_{t}}=\beta E_{t}\left\{\left(\frac{\lambda_{t+1}}{P_{t+1}}\right)\left[\tilde{P}_{t+1} z_{t+1} f\left(h_{t+1}\right)-W_{t+1} h_{t+1}-\frac{\phi}{\psi^{2}}\left(\exp \left[-\psi\left(\frac{W_{t+1}}{W_{t}}-1\right)\right]+\psi\left(\frac{W_{t+1}}{W_{t}}-1\right)-1\right) P_{t+1}+(1-\rho) \mu_{t+1}\right]\right\}$

$\frac{\lambda_{t}}{P_{t}} E_{t}\left[-\gamma P_{t}+(1-\rho) q_{t}\left(\theta_{t}\right) \mu_{t}\right]=0$

Combining the two FOCs gives the Job Creation $(J C)$ condition:

$$
\frac{\gamma}{q\left(\theta_{t}\right)}=\beta(1-\rho) E_{t}\left\{\left(\frac{\lambda_{t+1}}{\lambda_{t}}\right)\left[\varphi_{t+1} z_{t+1} f\left(h_{t+1}\right)-w_{t+1} h_{t+1}-\frac{\phi}{\psi^{2}}\left(\exp \left[-\psi\left(\pi_{t+1}^{w}-1\right)\right]+\psi\left(\pi_{t+1}^{w}-1\right)-1\right)+\frac{\gamma}{q\left(\theta_{t+1}\right)}\right]\right\}
$$

which, using condition (3) can be written as 
$\frac{\gamma}{q\left(\theta_{t}\right)}=\beta(1-\rho) E_{t}\left\{\left(\frac{u_{c t+1}}{u_{c t}}\right)\left[\varphi_{t+1} z_{t+1} f\left(h_{t+1}\right)-w_{t+1} h_{t+1}-\frac{\phi}{\psi^{2}}\left(\exp \left[-\psi\left(\pi_{t+1}^{w}-1\right)\right]+\psi\left(\pi_{t+1}^{w}-1\right)-1\right)+\frac{\gamma}{q\left(\theta_{t+1}\right)}\right]\right\}$

Thus, the firm equates in equilibrium the vacancy-creation cost to the discounted expected value of profits from the match. As the term in brackets makes clear, the flow profit to a firm from a match equals output net of wage payments and costs of adjusting wages. ${ }^{6}$ This condition is also referred to as the free entry condition for posting vacancies. Note that in the above expression $\varphi_{t}$ is the real price of intermediate goods (i.e. $\varphi_{t}=\frac{\tilde{P}_{t}}{P_{t}}$ ) and $w_{t}$ is the real wage, $w_{t}=\frac{W_{t}}{P_{t}}$.

\subsubsection{Retail Sector}

Retailers buy the intermediate good and transform it into a differentiated final good using a one to one constant return to scale technology. The real marginal cost of a retailer is thus the real price of the intermediate good (i.e. $\varphi_{t}$ ). Following Thomas (2008), Gertler, Sala and Trigari (2008) and Trigari (2006), I assume that price rigidity in this economy arises in the final goods sector. A retailer incurs a (total) real cost of adjusting prices given by the typical Rotemberg (1982) quadratic adjustment cost:

$\Phi_{j t}^{P}=\frac{\phi^{p}}{2}\left(\frac{P_{j t}}{P_{j t-1}}-1\right)^{2} y_{j t}$

With this formulation, I assume that the adjustment cost function of prices is symmetric. As shown by Kim and Ruge-Murcia (2009), this assumption is supported by U.S. data.

${ }^{6}$ To see this clearly, one may write this condition in the following way

$\gamma=q\left(\theta_{t}\right)(1-\rho) E_{t}\left\{\left(\beta \frac{u_{c t+1}}{u_{c t}}\right)\left[\varphi_{t+1} z_{t+1} f\left(h_{t+1}\right)-w_{t+1} h_{t+1}-\frac{\phi}{\psi^{2}}\left(\exp \left[-\psi\left(\pi_{t+1}^{w}-1\right)\right]+\psi\left(\pi_{t+1}^{w}-1\right)-1\right)+\frac{\gamma}{q\left(\theta_{t+1}\right)}\right]\right\}$

The LHS is the cost of posting a vacancy. The RHS shows the discounted expected value of profits from a given match. The firm enjoys profits from this match in case of being filled (which occurs with probability $q\left(\theta_{t}\right)$ ) and surviving exogenous separation (which occurs with probability $(1-\rho)$ ). We can use the last term in the RHS to iterate forward and hence get the expected PDV of profits. In short, this equation equates the cost of posting a vacancy (the LHS) to the (expected) benefit of posting that vacancy. 
The problem of a retailer is to choose its price $P_{j t}$ to maximize profits subject to the demand for its good, as follows (with $m c_{t}=\varphi_{t}$ ):

$$
\operatorname{MaxE}_{0} \sum_{t=0}^{\infty} \beta^{t}\left\{\frac{\lambda_{t}}{\lambda_{0} P_{t}}\left[P_{j t} y_{j t}-P_{t} m c_{j t} y_{j t}-\frac{\phi^{p}}{2}\left(\frac{P_{j t}}{P_{j t-1}}-1\right) P_{t} y_{j t}\right]\right\}
$$

s.t.

$$
y_{j t}=\left[\frac{P_{j t}}{P_{t}}\right]^{-\varepsilon} y_{t}
$$

By taking first order conditions and assuming symmetry among firms (since they all set the same price in equilibrium), we get the following Price Philips Curve:

$$
1-\phi^{p}\left(\pi_{t}-1\right) \pi_{t}+\beta \phi^{p} E_{t}\left[\left(\frac{u_{c t+1}}{u_{c t}}\right)\left(\pi_{t+1}-1\right) \pi_{t+1} \frac{y_{t+1}}{y_{t}}\right]=\varepsilon\left(1-m c_{t}\right)
$$

This equation collapses in the case of fully flexible prices $\left(\phi^{p}=0\right)$ or fully stable prices $\left(\pi_{t}=1\right.$ for all $t$ ) to the familiar condition, $m c_{t}=\frac{\varepsilon-1}{\varepsilon}$, the inverse of the price markup.

\subsection{Nash Bargaining}

As is typical in the literature, wage payments and hours per employed individual are determined by Nash bargaining between firms and individuals. I follow Thomas (2008) and Arseneau and Chugh (2008) among others by assuming that bargaining occurs over nominal wages $W_{t}$ rather than real wages $w_{t}$ (as typically has been the assumption). This assumption helps to focus on nominal wages, which are the subject of this study. To see this, note that to have a good notion for downward wage rigidity one should focus on the determination of nominal wages, since if bargaining is over real wages, downward real wage rigidity will have no implications for monetary policy. As discussed in Fahr and Smets (2008), Downward Real Wage Rigidity means than nominal wages are indexed to inflation, which in case of full 
indexation implies a zero greasing inflation rate. Put differently, the fact that real wages cannot fall following negative shocks regardless of the inflation rate makes grease inflation insignificant. Given that deviation from price stability is costly, optimal policy will fully stabilize prices. This renders the discussion here less relevant.

In line with previous literature, firms and workers split the surplus of a match according to their bargaining power. Prior to presenting the bargaining problem it is useful to define the asset values for employed workers, unemployed individuals and firms. The asset value for an employed worker from a job is given by

$$
V_{t}^{W}=W_{t} h_{t}-\frac{P_{t} v\left(h_{t}\right)}{u_{c t}}+\beta E_{t}\left[\left(\frac{u_{c t+1}}{u_{c t}}\right)\left(\frac{P_{t}}{P_{t+1}}\right)\left((1-\rho) V_{t+1}^{W}+\rho V_{t}^{U}\right)\right]
$$

where following the literature, the disutility from work is expressed in terms of the marginal utility of consumption (and hence it is equal to the marginal rate of substitution between consumption and labor). Therefore, the asset value for an employed individual is the difference between his current wage payment and the disutility from labor together with the discounted continuation value of staying employed or becoming unemployed next period, with the two taking place with probabilities $(1-\rho)$ and $\rho$, respectively.

Similarly, the asset value for an unemployed worker can be expressed as

$$
V_{t}^{U}=P_{t} b+\beta E_{t}\left[\left(\frac{u_{c t+1}}{u_{c t}}\right)\left(\frac{P_{t}}{P_{t+1}}\right)\left(\theta_{t} q\left(\theta_{t}\right)(1-\rho) V_{t+1}^{W}+\left(1-\theta_{t} q\left(\theta_{t}\right)(1-\rho)\right) V_{t+1}^{U}\right)\right],
$$

which equals to unemployment benefits and the continuation value. The later is the weighted sum of the values of staying unemployed next period (which occurs with probability $\left(1-\theta_{t} q\left(\theta_{t}\right)(1-\rho)\right)$ ) and becoming employed (which occurs with probability $\theta_{t} q\left(\theta_{t}\right)(1-\rho)$ ).

Finally, the value of a filled job for the firm is

$$
V_{t}^{V}=\tilde{P}_{t} z_{t} f\left(h_{t}\right)-W_{t} h_{t}-\frac{\phi}{\psi^{2}}\left(\exp \left[-\psi\left(\frac{W_{t}}{W_{t-1}}-1\right)\right]+\psi\left(\frac{W_{t}}{W_{t-1}}-1\right)-1\right) P_{t}+\beta E_{t}\left[\left(\frac{u_{c t+1}}{u_{c t}}\right)\left(\frac{P_{t}}{P_{t+1}}\right)(1-\rho) V_{t+1}^{V}\right]
$$


Therefore, the value of each match equals the flow value of its product net of wage payments and wage adjustment costs plus the continuation value of that match in case of surviving separation.

The Nash bargaining problem is to choose $W_{t}$ and $h_{t}$ to maximize

$\left(V_{t}^{W}-V_{t}^{U}\right)^{\eta} V_{t}^{V^{1-\eta}}$

where $\eta$ denotes the bargaining power of workers (and their share in the matching surplus). Note that in equilibrium, the value of posting a vacancy is zero and hence the threat point of firms is set to zero in the above formulation. The first order condition with respect to $W_{t}$ is

$\eta\left(V_{t}^{W}-V_{t}^{U}\right)^{\eta-1}\left(\frac{\partial V_{t}^{W}}{\partial W_{t}}-\frac{\partial V_{t}^{U}}{\partial W_{t}}\right) V_{t}^{V^{1-\eta}}+(1-\eta) V_{t}^{V^{-\eta}} \frac{\partial V_{t}^{V}}{\partial W_{t}}\left(V_{t}^{W}-V_{t}^{U}\right)^{\eta}=0$

Denoting the effective bargaining power of workers by $\omega_{t}$, the FOC with respect to $W_{t}$ can be rewritten as

$\left(V_{t}^{W}-V_{t}^{U}\right)=\frac{\omega_{t}}{\left(1-\omega_{t}\right)} V_{t}^{V}$

with $\omega_{t}=\frac{\eta}{\eta+(1-\eta) \frac{\Delta_{t}^{F}}{\Delta_{t}^{W}}}, \quad \Delta_{t}^{W}=-\left(\frac{\partial V_{t}^{W}}{\partial W_{t}}-\frac{\partial V_{t}^{U}}{\partial W_{t}}\right)$ and $\Delta_{t}^{F}=\frac{\partial V_{t}^{V}}{\partial W_{t}}$.

If nominal wages are costless to adjust, $\omega_{t}$ will be exactly equal to $\eta$. The wage adjustment cost drives a wedge between the effective and the ex-ante bargaining powers. Also, since the parameter $\psi$ appears in the expression for $\frac{\partial V_{t}^{V}}{\partial W_{t}}$, the presence of DNWR plays here a role in determining the effective bargaining power of workers. As $\psi$ increases, the cost of increasing wages becomes very low and hence the effective bargaining power approaches its ex-ante value, $\eta$.

Combining the job creation expression (17) with the asset value for the firm from a match (24) gives 
$V_{t}^{V}=\tilde{P}_{t} z_{t} f\left(h_{t}\right)-W_{t} h_{t}-\frac{\phi}{\psi^{2}}\left(\exp \left[-\psi\left(\pi_{t}^{w}-1\right)\right]+\psi\left(\pi_{t}^{w}-1\right)-1\right) P_{t}+\frac{\gamma P_{t}}{q\left(\theta_{t}\right)}$

It is evident that the more downwardly rigid nominal wages, the lower the value to a firm from a given match.

Also, substituting the expression for $J$ yields the wage setting equation that characterizes the real wage rate agreed upon

$$
\frac{\omega_{t}}{1-\omega_{t}}\left[\varphi_{t} z_{t} f\left(h_{t}\right)-w_{t} h_{t}-\frac{\phi}{\psi^{2}}\left(\exp \left[-\psi\left(\pi_{t}^{w}-1\right)\right]+\psi\left(\pi_{t}^{w}-1\right)-1\right)+\frac{\gamma}{q\left(\theta_{t}\right)}\right]=w_{t} h_{t}-\frac{v\left(h_{t}\right)}{u_{c t}}-b+E_{t}\left[\frac{\omega_{t+1}}{1-\omega_{t+1}}\left(\frac{\gamma}{q\left(\theta_{t}\right)}-\gamma \theta_{t}\right)\right]
$$

The current wage is affected by the cost of adjusting nominal wages, the outside options $(b)$, the disutility from labor and the continuation values of the worker being employed.

Finally, the equation characterizing the determination of hours per employed is given by

$$
\frac{\Gamma_{t}}{1-\Gamma_{t}}\left[\varphi_{t} z_{t} f\left(h_{t}\right)-w_{t} h_{t}-\frac{\phi}{\psi^{2}}\left(\exp \left[-\psi\left(\pi_{t}^{w}-1\right)\right]+\psi\left(\pi_{t}^{w}-1\right)-1\right)+\frac{\gamma}{q\left(\theta_{t}\right)}\right]=w_{t} h_{t}-\frac{v\left(h_{t}\right)}{u_{c t}}-b+E_{t}\left[\frac{\Gamma_{t+1}}{1-\Gamma_{t+1}}\left(\frac{\gamma}{q\left(\theta_{t}\right)}-\gamma \theta_{t}\right)\right]
$$

Where, $\Gamma_{t}=\frac{\eta}{\eta+(1-\eta) \frac{\delta_{t}^{F}}{\delta_{t}^{W}}}, \delta_{t}^{W}=-\frac{\partial \mathrm{W}_{\mathrm{t}} / \partial h_{t}}{P_{t}}$ and $\delta_{t}^{F}=\frac{\partial \mathrm{J}_{\mathrm{t}} / \partial h_{t}}{P_{t}}$

To find expression (30), the FOC with respect to $h$ was transformed into $\left(V_{t}^{W}-V_{t}^{U}\right)=\frac{\Gamma_{t}}{\left(1-\Gamma_{t}\right)} V_{t}^{V} \cdot{ }^{7}$

${ }^{7}$ Condition (29) can also be written in the following way:

$$
w_{t} h_{t}=\omega_{t}\left[\varphi_{t} z_{t} f\left(h_{t}\right)-\frac{\phi}{\psi^{2}}\left(\exp \left[-\psi\left(\pi_{t}^{w}-1\right)\right]+\psi\left(\pi_{t}^{w}-1\right)-1\right)+\frac{\gamma}{q\left(\theta_{t}\right)}\right]+\left(1-\omega_{t}\right)\left[\frac{v\left(h_{t}\right)}{u_{c t}}+b\right]+E_{t}\left[\frac{\omega_{t+1}\left(1-\omega_{t}\right)}{1-\omega_{t+1}}\left(\gamma \theta_{t}-\frac{\gamma}{q\left(\theta_{t}\right)}\right)\right]
$$

Therefore, the wage paid to a worker is a weighted average of the value of his output (net of wage adjustment costs), the value of his outside options, the disutility of work, and the present discounted value of his expected gain from search. In the absence of wage adjustment costs, this expression collapses to the more familiar equation

$$
w_{t} h_{t}=\eta\left[\varphi_{t} z_{t} f\left(h_{t}\right)+\gamma \theta_{t}\right]+(1-\eta)\left[\frac{v\left(h_{t}\right)}{u_{c t}}+b\right]
$$

Hence, the real wage of a worker is equal to the share $\eta$ of the revenue and saving of hiring costs, and he is compensated by the share $(1-\eta)$ of the disutility from supplying work and the foregone unemployment benefits. 


\subsection{The Private Sector Equilibrium}

Before discussing the optimal monetary policy problem, I briefly present the private sector equilibrium. The equilibrium conditions of the private sector are the consumption Euler equation (5) describing intertemporal choices, the law of motion for employment (13), the job creation condition (17), the Price Philips Curve (21), the wage setting equation (29), the hours determination equation (30), the resource constraint of the economy given by

$n_{t} z_{t} h_{t}^{\alpha}-c_{t}-\gamma \theta_{t} u_{t}-\frac{\phi}{\psi^{2}}\left(\exp \left[-\psi\left(\pi_{t}^{w}-1\right)\right]+\psi\left(\pi_{t}^{w}-1\right)-1\right) n_{t}-\frac{\phi^{p}}{2}\left(\pi_{t}-1\right)^{2} n_{t} z_{t} h_{t}^{\alpha}=0$

the constraint on unemployment

$$
u_{t}=1-n_{t}
$$

and finally, the identity describing the real wage growth (33), which is typically introduced in sticky price-sticky wage models. As explained in Chugh (2006) and Arseneau and Chugh (2008), this identity does not hold trivially in the case of rigid nominal wages and hence it should be added to the equilibrium conditions of the private sector. ${ }^{8}$

$$
\frac{w_{t}}{w_{t-1}}=\frac{\pi_{t}^{w}}{\pi_{t}}
$$

Note that in condition (31), I substitute for $v_{t}$ using the expression for labor market tightness $\left(v_{t}=\theta_{t} u_{t}\right)$.

Definition 1: Given the exogenous processes $\left\{R_{t}, z_{t}\right\}$, the private sector equilibrium is a sequence of allocations $\left\{c_{t}, h_{t}, n_{t}, u_{t}, \theta_{t}, \varphi_{t}, w_{t}, \pi_{t}, \pi_{t}^{w}\right\}$ that satisfy the equilibrium conditions $5,13,17,21,29,30$, 31,32 and 33 .

\footnotetext{
${ }^{8}$ This constraint has been also considered in the study of Erceg, Henderson and Levin (2000).
} 


\subsection{Optimal Monetary Policy Problem}

The monetary authority in this economy seeks to maximize the household's welfare subject to the resource constraint and the first order conditions of individuals and firms. Formally, given the exogenous process for technology $z_{t}$, the monetary authority chooses $\left\{c_{t}, h_{t}, n_{t}, u_{t}, \theta_{t}, \varphi_{t}, w_{t}, \pi_{t}, \pi_{t}^{w}\right\}$ in order to maximize (1) subject to $13,17,21,29,30,31,32$ and 33.

In the formulation of the optimal monetary policy problem, I assume that the monetary authority does not commit to any Taylor-type rule. It instead chooses allocations in order to maximize the welfare of individuals. One may also consider the case where the monetary authority chooses allocations subject to an interest-rate rule, as for example has been assumed in Faia (2008).

Definition 2: Given the exogenous process for $z_{t}$, the problem of the monetary authority is to choose allocations $\left\{c_{t}, h_{t}, n_{t}, u_{t}, \theta_{t}, \varphi_{t}, w_{t}, \pi_{t}, \pi_{t}^{w}\right\}$ to maximize lifetime utility subject to the conditions 13,17 , $21,29,30,31,32$ and 33 . 


\section{Calibration}

This section presents the parameterization of the model and the calibration procedure. The first subsection discusses the parameterization of the model. Subsection 3.2 then presents some discussion about the calibration methodology applied in this study.

\subsection{Parameterization:}

Following Trigari (2006) and Christoffel et al.(2008) among others, I assume the following period utility function:

$u\left(c_{t}, h_{t}, n_{t}\right)=\frac{c_{t}^{1-\sigma}}{1-\sigma}-n_{t} \frac{\chi}{1+\vartheta} h_{t}^{1+\vartheta}$

I assume a time unit of a quarter and hence the discount factor $\beta$ is set to 0.99 . Following previous literature I set the parameter $\sigma$ to 2 . $\vartheta$ is set at 2, implying a labor supply elasticity of $0.5 .^{9}$ I then calibrate $\chi$ such that SS level of hours is 0.3 , as is conventional in literature. In calibration $\chi$ I follow the procedure of Trigari (2006).

Firms produce using the following diminishing-return-in-labor production function

$f\left(h_{t}\right)=h_{t}^{\alpha}$

$\alpha$ is set to $2 / 3$ implying a labor share of about $67 \%$, in line with literature.

The matching process between firms and workers is governed by the following constant returns to scale function:

$m\left(v_{t}, u_{t}\right)=\sigma_{m} u_{t}^{\zeta} v_{t}^{1-\zeta}$

The parameter $\zeta$ measures the elasticity of matches with respect to unemployment and is set here to 0.40 in line with several studies (e.g. Arseneau and Chugh, 2008 and Faia, 2008). The parameter $\sigma_{m}$ measures the efficiency of the matching process and it is calibrated in my benchmark case to be

${ }^{9}$ Previous studies considered elasticity between 0.1 and 1 , corresponding to values of 10 and 1 for $\vartheta$, respectively. I choose here an intermediate value for the elasticity of hours. 
0.658. This value has been calibrated assuming that the probability to fill a vacancy is 0.7 and the probability to find a job is 0.6 , as conventional in literature. Given the assumed matching function this implies a SS value of 6/7 for labor market tightness. I therefore calibrate the value of posting vacancies $\gamma$

to match this SS level of $\theta$. The value obtained for $\gamma$ is 0.413. Also, following Shimer (2005) and Arseneau and Chugh (2008), among others, I will set the quarterly separation rate $\rho$ at 0.10 .

As is standard in literature, I assume that the Hosios (1990) condition holds and hence that the Nash bargaining power of workers is equal to the contribution of an unemployed individual to the match (i.e. $\eta=\zeta=0.40)$. As shown in Hosios (1990), this condition guarantees the efficiency of the matching process.

Productivity is governed by the following AR(1) process

$\ln \left(z_{t}\right)=\rho_{z} \ln \left(z_{t-1}\right)+\varepsilon_{t}$

$\rho_{z}$ is set to 0.95 in line with previous literature. The innovation term $\varepsilon_{t}$ is normally distributed with zero mean and a standard deviation of $\sigma_{\varepsilon}=0.007$, as typically assumed in literature.

The parameters governing the adjustment cost functions of prices and nominal wages (i.e. $\phi^{p}, \phi$ and $\psi$ ) are estimated using the Simulated Method of Moments (SMM). In my baseline calibration, I choose the following second moments to match: the standard deviations of consumption, wage inflation, price inflation, real wages, hours per employed individual and employment. However, as robustness, I also redo my work using other groups of moments to match. The calibrated parameters in my baseline calibration are $\phi^{p}=26.9, \phi=87.3$ and $\psi=2567.3$.

\subsection{Computational Solution}

The main purpose of the paper is to address optimal monetary policy in the presence of asymmetries in nominal wage adjustment. For this purpose, one needs to apply second order approximations for the monetary authority's equilibrium conditions. Linearization cannot account for this asymmetry since, by construction, it eliminates the asymmetries of the model. Following recent literature (e.g. Fahr and Smets, 2008) I will apply the second order approximation procedure proposed by Schmitt-Grohe and Uribe (2004). I first start by briefly describing the deterministic steady state and then present the simulations of the model economy, particularly following adverse productivity shocks. 


\section{Optimal Monetary Policy}

This section presents the main findings regarding optimal monetary policy under search and matching frictions in the presence of downward rigidity in nominal wages. I first discuss the steady state results of the paper and then turn to the dynamics of the model.

\subsection{The Deterministic Steady State Optimal Inflation Rate}

Before turning to present the optimal grease inflation rate, a note on the deterministic steady state is in order. The deterministic steady state of the model is invariant to the degrees of price stickiness, wage stickiness and to the degree of asymmetry in the adjustment of wages. In the absence of shocks, inflation is not beneficial, and due to the direct cost of deviation from complete price stability, the monetary authority completely stabilizes prices (and nominal wages) in the deterministic steady state. This fact is unrelated to whether wages are flexible or rigid.

\subsection{The Optimal Grease Inflation Rate}

In this subsection I discuss the dynamics of the model. As a benchmark, I first show the case with fully flexible wages (i.e. $\phi=0$ ). When wages are costless to adjust, and prices are rigid, optimal monetary policy fully stabilizes prices (Table 1). In this case, all the adjustment in real wages occurs through instantaneous adjustment of nominal wages. When nominal wages are rigid, but the adjustment cost function is symmetric, optimal grease inflation rate is very close to full price stability: the symmetry of the wage adjustment cost eliminates the precautionary motive for inflation.

However, and this is the main result of the study, when nominal wages are downwardly rigid, optimal monetary policy deviates from full price stability. The optimal annual grease inflation rate is 2.15 percent. Positive inflation allows for real wages to adjust and thus eases job creation. In a model with explicit extensive margin, the role of inflation is crucial: unemployment is far more volatile than hours per worker (both in data and in the model). Since the monetary authority is concerned about fluctuations in unemployment, the monetary authority tries to limit the size of increase in unemployment following the negative shock by inflating. To see this, consider a model where the monetary authority commits to zero inflation rate at all dates and states. In such a model, the combination of downwardly rigid wages and 
stable prices limits (significantly) the size of the drop in real wages. Hence, the unemployment rate increases far beyond its value in the benchmark model (to 0.1714) and become significantly more volatile (a standard deviation of 13.1669). On the other hand, vacancies drop stronger than under the benchmark model (to 0.1215 , with a standard deviation of 16.1618). Output, and hence consumption, drop strongly as well. $^{10}$

\begin{tabular}{l|cc|cc|cc}
\hline & \multicolumn{2}{|c|}{ I } & \multicolumn{2}{c|}{ II } & \multicolumn{2}{c}{ III } \\
\hline & \multicolumn{2}{|c|}{$\begin{array}{c}\text { Fully Flexible Wages } \\
(\phi=0)\end{array}$} & \multicolumn{2}{c}{$\begin{array}{c}\text { Rigid Wages, } \\
\text { Symmetric Adjustment } \\
\text { Cost }(\psi=0)\end{array}$} & $\begin{array}{c}\text { Rigid Wages, } \\
\text { Asymmetric Adjustment } \\
\text { Cost }(\psi=2567.3)\end{array}$ \\
\hline$x$ & $\mu_{x}$ & $\sigma_{x}$ & $\mu_{x}$ & $\sigma_{x}$ & $\mu_{x}$ & $\sigma_{x}$ \\
\hline$\pi$ & -0.0013 & 0.3233 & 0.0027 & 0.5605 & 2.1505 & 3.7184 \\
$\pi^{w}$ & 0.0190 & 2.0317 & 0.0003 & 0.1362 & 2.1204 & 2.9052 \\
\hline$y$ & 0.3782 & 1.1189 & 0.3782 & 1.1718 & 0.3801 & 1.3507 \\
$c$ & 0.3229 & 1.0238 & 0.3229 & 0.9287 & 0.3237 & 1.1530 \\
$h$ & 0.3000 & 0.2596 & 0.3000 & 0.3021 & 0.3009 & 0.4702 \\
$w$ & 1.1178 & 2.7432 & 1.1176 & 1.9594 & 1.1132 & 2.4304 \\
$u$ & 0.1563 & 1.7040 & 0.1563 & 1.9656 & 0.1583 & 3.6871 \\
$v$ & 0.1339 & 1.7194 & 0.1339 & 1.9965 & 0.1361 & 4.1440 \\
$\theta$ & 0.8576 & 2.9148 & 0.8576 & 3.3697 & 0.8859 & 7.4962 \\
\hline
\end{tabular}

Table 1: Simulated moments- Second order approximation. $\phi=26.9$ and $\phi^{p}=87.3$. $\mu_{x}$ - the mean of the variable. $\sigma_{x}$ - the standard deviation of the variable (in percents).

Price inflation and wage inflation are presented in annualized terms.

Figure 1 also helps to shed light on his result. This figure assumes that the monetary authority commits to a certain inflation target at all dates and states. The figure shows the mean levels and standard deviations of unemployment and vacancies as a function of the inflation target (ranging between zero and 3\%). One can see that unemployment drops significantly in the range between zero inflation rate and about $2 \%$. On the other hand, vacancy posting increases significantly in this range. The standard deviations of both variables fall considerably as the target increases in this range. Basically, this figure tells two important points: first, inflation is more important in "greasing" the wheels of the labor market for low inflation rates, as expected. In addition, the trade-off between inflation and unemployment is more significant for rates of inflation. Second, the marginal "benefit" from increasing the inflation rate

${ }^{10} \mathrm{I}$ will return to this point in section 6 , where I present the impulse responses under a policy that fully commits to stabilize prices vs. the optimal policy. 
approaches zero as we move above approximately $2 \%$. This observation just supports the finding of a grease inflation of slightly above $2 \%$.

As for labor market variables (unemployment, vacancies and labor market tightness), their calibrated standard deviations are well below their values in actual U.S. data (see e.g. Shimer, 2005). The failure of the labor search and matching model to account for the true volatilities of labor market aggregates is well documented in literature since Shimer's (2005) seminal paper. The model, however, manages to capture the volatilities of $v$ and $u$ relative to the volatility of $\theta u$, as shown in data. Note also that the model with DNWR better account for the volatilities of these three variables compared to the other two alternatives. ${ }^{11}$

\subsection{The Optimal Inflation Rate- Sensitivity Analyses}

The goal of this subsection is to check whether the main result of this paper (i.e. the optimal long run inflation rate is around 2 percents) still holds once different empirical moments to match are chosen. The results are shown in Table 2. In general, I choose here two different cases: in the first, I allow for only 3 moments to match (and so the number of moments equals the number of parameters). In the second, the number of moments exceeds the number of parameters.

The results show that the long run inflation rate is usually around 2 percents, ranging from about 1.80 percents to about 2.44 percents. The higher inflation rate in the latter case (where the standard deviation of labor market tightness is targeted) is due to the fact that in order to account for the high standard deviation of labor market tightness, a higher $\psi$ is needed. This in turn leads to a higher inflation rate.

In general, the analyses in this subsection confirm my earlier result; the optimal long run inflation rate in a model with DNWR and labor market frictions is about 2 percent. This result is robust to the choice of moments to match. In addition, all cases considered the optimal grease inflation rate is considerably higher than the optimal grease inflation rate in Kim and Ruge-Murcia $(2007,2009)$.

\footnotetext{
${ }^{11}$ The volatility of real wages in this model is considerably higher than in actual data. High standard deviation of real wages is the typical finding of labor search models. As noted in Arseneau and Chugh (2008), the relatively variable real wages are not undesirable since the main role wages play is distributive rather than allocative (as in the neoclassical model). Also, movements in real wages help job creation and they enhance the adjustment of the economy to the shock. Real wages fluctuate regardless of nominal wages being fully flexible or rigid; in the latter case, prices will allow for the required adjustment in real wages.
} 


\section{Impulse Responses}

This subsection describes, under the optimal policy, the behavior of the economy following a negative productivity shock and compares its behavior to the response to a positive productivity shock. Figure 2 shows the behavior of the main variables of interest under the presence of DNWR. The first main observation is the asymmetry in the response of these variables to negative and positive shocks of the same magnitude. Nominal wages do not almost fall following a negative shock, but they increase considerably following a positive shock. The asymmetry in the response of nominal wages is more significant the bigger the size of the shock. When the negative shock is of a big size (of two standard deviation size), DNWR becomes more important, since in this case the required fall in real wages is naturally bigger. Hence, more asymmetry is observed in the behavior of the economy following big shocks of different directions and same magnitudes.

Following a negative productivity shock, inflation increases considerably. It, however, falls only slightly below its SS level following a positive shock of the same magnitude. The asymmetry is even more significant when the shock has a bigger size. This finding confirms the role of inflation in greasing the wheels of the labor market following negative shocks, given nominal wages being downwardly rigid.

Figure 2 also shows asymmetry in the response of unemployment to productivity shocks, particularly those of a big size. This asymmetry is less than the asymmetry of price inflation and wage inflation. This is a result of less asymmetry in the behavior of real wages: since prices and nominal wages almost complement each other following shocks, the fall in real wages following a negative shock (which almost entirely occurs through the increase in prices) is almost the same, in absolute terms, as the increase in real wages following a positive shock (in which case the adjustment is through both prices and nominal wages). But, since real wages is what matters eventually, the asymmetry in unemployment is smaller. Note also that in the case of a big shock, unemployment is more persistent.

Other variables also display asymmetry in their response to negative and positive shocks. This is particularly the case of vacancies, labor market tightness and the marginal cost of retailers. The asymmetry in the behavior of vacancies coupled with the asymmetry in the behavior of unemployment explains the asymmetry in the behavior of labor market tightness. Finally, there seems to be little asymmetry in the behavior of output and consumption. This is perhaps due to the symmetry in the productivity shock and the relatively small degree of asymmetry in unemployment. 
It is also interesting to contrast the behavior of the economy following shocks under the presence of DNWR to its behavior under symmetric adjustment cost function. Figure 3 displays the response of the economy to positive and negative shocks in the absence of DNWR. It is evident that all variables display symmetry in their response to positive and negative shocks, as expected.

For completeness, I show the response of the economy to a negative shock in the three possible cases: fully flexible nominal wages, symmetric nominal wage adjustment cost and DNWR (Figure 4). When nominal wages are fully flexible, not only that inflation is set at zero on average (recall Table 1), but inflation is also irresponsive on impact. Given that prices are costly to adjust and nominal wages are fully flexible, nominal wages fall instantaneously to allow for the drop in real wages. The role of the downward rigidity is clearly revealed in this case: the response of inflation to a negative shock under downwardly nominal wages is significantly larger than its response under rigid, but symmetric, adjustment cost.

The fall in real wages under fully flexible nominal wages is considerably larger than under wage rigidity (of either type). Unemployment increase only slightly under fully flexible wages and it displays less persistence. In addition, the fall on vacancies and labor market tightness is considerably smaller under fully flexible nominal wages than under rigid wages. The larger falls in unemployment and hours under rigid wages than under fully flexible nominal wages lead to larger drops in output and consumption. In overall, and as expected, the case of symmetrically rigid wages is an intermediate case between the cases of fully flexible wages and downwardly rigid wages.

The discussion on optimal monetary policy can be summarized as follows. Under fully flexible nominal wages, inflation does not respond to negative shocks and it is always set at zero. When nominal wages are rigid and the adjustment cost function is symmetric, inflation responds to shocks but it is kept very close to zero. Finally, when nominal wages are downwardly rigid, the response of inflation is stronger on impact and monetary policy deviates, on average, from full price stability. 


\section{Price Stabilization vs. Unemployment Stabilization}

This section considers the performances of two extreme polices relative to the benchmark case (i.e. optimal policy). In the first case, the monetary authority commits to full stabilization of prices at all dates and states (to which I refer as strict inflation targeting). In the second, monetary authority commits to stabilize unemployment at its steady state level.

When the monetary authority strictly targets inflation, unemployment responds more strongly than under the optimal policy (Figure 5). The initial response of unemployment for a shock of one standard deviation size is significantly larger than under the benchmark model. The peak on the response, after about 3 quarters, is about three times as large under strict inflation targeting as under optimal policy. In addition, unemployment displays considerably more persistence strict inflation targeting. In either case, unemployment displays the typical humped-shaped pattern that has been observed in previous studies (e.g. Blanchard and Gali, 2008; Krause and Lubik, 2007).

Wage inflation falls more under strict inflation targeting than under constant unemployment and optimal policy (although in either case, the fall in wage inflation is very small due to the presence of DNWR). Since prices are fully stabilized, nominal wages fall by more than under optimal policy in order to allow for real wage adjustments. Note that the behavior of nominal wages under the constant unemployment regime is almost the same as under optimal policy.

When the monetary authority fully stabilizes unemployment, inflation responds stronger on impact. Intuitively, if unemployment cannot increase to cope with the negative shock, prices will absorb the shock almost entirely. It is interesting, however, to notice that after about 4 quarters, the behavior of inflation under the constant unemployment regime is similar to its behavior under optimal policy. In either case, inflation exhibits a lower degree of persistence than unemployment.

The downward rigidity in nominal wages, coupled with full price stability, limit the size of the drop in the real wage under strict inflation targeting (in this regard, the downward rigidity in nominal wages is translated into downward real wage rigidity). Under strict inflation targeting, the fall in the real wage is less than under both the constant unemployment regime and optimal policy. The highest initial drop in the real wage is under the constant unemployment regime since in this case nominal wages fall as under optimal policy but inflation displays higher response. This result is as expected since, when the monetary authority commits to fully stable employment, real wages must fall significantly for the economy to adjust to the negative productivity shock. 
Following the behavior of employment, the largest drop in output is under strict inflation targeting. Clearly, this drop is the largest after about 3 quarters, when unemployment peaks (and also since the drop in hours per worker is the largest). Also, the behavior of consumption is similar to the behavior of output and the largest fall in labor market tightness is under strict inflation targeting- vacancies fall strongly and unemployment increases considerably.

In short, the analysis here confirms that strict inflation targeting is far from being optimal. Full stabilization of prices in the presence of downward rigidity in nominal wages limits the ability of the economy to adjust to adverse shocks considerably. Stabilizing unemployment, however, delivers similar behavior of the economy as under optimal policy. Welfare analysis shows that welfare under a zero inflation policy is lower by around 8.48 percent than welfare under the optimal policy. Welfare under full stabilization of unemployment is lower by only 0.30 percent than welfare under optimal policy.

My results are in line with recent studies that suggest the need for deviations from full price stability and a response to unemployment. Blanchard and Gali (2008) show that strict inflation targeting delivers a welfare loss which is more than twice as large as under full stabilization of unemployment. Faia (2008) suggests that, in the presence of real wage rigidities, the optimal Taylor-type rule should respond to unemployment alongside with inflation. Thomas (2008) also argues for non full stabilization of prices following shocks when nominal wages are rigid. Although these studies and the current one may differ in their focus (i.e. the type of wage rigidity), they all suggest that optimal policy should deviate from price stability following shocks. This study shows that DNWR also leads to a significant deviation from full price stability on average as a precautionary motive. 


\section{Conclusion}

This paper studies optimal monetary policy within a labor search and matching framework in the presence of downwardly rigid nominal wages. The paper shows that, when nominal wages are downwardly rigid, the optimal grease inflation rate is around 2.0 percent. This grease inflation rate is significantly higher than the counterpart in Kim and Ruge-Murcia (2009). Optimal monetary policy deviates from full price stability to allow for real wage adjustments, particularly following adverse shocks, and hence it helps job creation and prevents excessive increase in unemployment. In a model with a commitment to zero inflation rate, unemployment responds significantly stronger relative the benchmark model that allows for price changes. In addition, in a model where prices are kept stable at all dates and states, unemployment displays significantly high volatility and it reaches a higher level on average. Vacancies, on the other hand, reach considerably low levels and become far more volatile, compared to optimal policy.

Moreover, the study shows asymmetry in the response of the economy to negative and positive shocks. The increase in inflation following an adverse productivity shock of a one standard deviation is considerably larger than the fall in inflation following a positive shock of the same magnitude. The asymmetry in the response of inflation is increasing with the size of the shock. Overall, the model reveals that DNWR leads to more asymmetries the bigger the sizes of the shocks are. DNWR is therefore a very challenging phenomenon in periods of severe recessions.

The current paper can be further extended. One possible extension is evaluating the performance of different Taylor-type rules compared to the optimal policy. Another extension is allowing for endogenous participation in the labor force. Finally, a future work may consider optimal fiscal policy in this environment. 


\section{References}

Altonji J. and Devereux P. (2000). "The Extent and Consequences of Downward Nominal Wage Rigidity," Research and Labor Economics, Vol. 19, pp. 383-431.

Andolfatto D.(1996.) "Business Cycles and Labor-Market Search." The American Economic Review, Vol. 86, pp. 112-132.

Arseneau D. Chugh S. (2008) “ Optimal Fiscal and Monetary Policy with Costly Wage Bargaining," Journal of Monetary Economics, Vol.55, pp.1401-1414.

Blanchard O. and Gali J. (2008) "Labor Markets and Monetary Policy: A New-Keynesian Model with Unemployment," NBER Working Paper, Number 13897.

Card D. and Hyslop D. (1997) "Does Inflation 'Grease the Wheels of the Labor Market," in Reducing Inflation: Motivation and Strategy, pp.71-122, Christina Romer and David Romer, Editors.

Chugh S. (2006) “ Optimal Fiscal and Monetary Policy with Sticky Prices and Sticky Wages,” Review of Economics Dynamics, Vol. 54, pp. 1809-1836.

Christoffel K., Costain J., de Walque G., Kuester K., Linzert T., Millard S. and Pierrard O. (2008) "Inflation Dyanmics with Search and Matching in the Labor Market: A Survey of Alternative Specifications," Mimeo.

Dickens W. et al. (2007a) "How Wages Change: Micro Evidence from the International Wage Flexibility Project," Journal of Economic Perspectives, Vol. 21, pp. 195-214.

Dickens W. et al. (2007b) "The Interaction of Labor Markets and Inflation: Micro Evidence from the International Wage Flexibility Project," The Brooking Institute.

Erceg C. , Henderson D. and Levin A. (2000) “ Optimal Monetary Policy with Staggered Wage and Price Contracts," Journal of Monetary Economics, Vol. 46, pp.281-313.

Faia E. (2008) “ Optimal Monetary Policy Rules with Labor Market Frictions," Journal of Economic Dynamics and Control, Vol. 32, pp. 1600-1621.

Fahr S. and Smets F. (2008) "Downward Wage Rigidities and Optimal Monetary Policy in a Monetary Union," Manuscript, The European Central Bank.

Fehr E. and Goette L. (2005) "Robustness and Real Consequences of Nominal Wage Rigidity," Journal of Monetary Economics, Vol. 52, pp. 779-804.

Gertler M. , Sala L. and Trigari A. (2008) "An Estimated Monetary DSGE Model with Unemployment and Staggered Nominal Wage Bargaining," Journal of Money, Credit and Banking, Vol.40, pp.17131764.

Gottschalk P. (2005) "Downward Nominal-Wage Flexibility: Real of Measurement Error?," Review of Economic and Statistics, Vol. 87, pp.556-568.

Kim J. and Ruge-Murcia F. (2007) "How Much Inflation is Necessary to Grease the Wheels," Universitie de Montreal, No. 2007-10. 
Kim J. and Ruge-Murcia F. (2009) "How Much Inflation is Necessary to Grease the Wheels," Journal of Monetary Economics, Vol. 56, pp.365-377.

Krause M. and Lubik T. (2007) "The (ir)relevance of Real Wage Rigidity in the New Keynesian Model with Search Frictions,” Journal of Monetary Economics, Vol. 54, pp.706-727.

Merz M. (1995) "Search in the Labor Market and the Real Business Cycle," Journal of Monetary Economics, Vol. 36, pp.269-300.

Mortensen D. and Pissarides C. (1994) "Job Creation and Job Destruction in the Theory of Unemployment," Review of Economic Studies, Vol. 61, pp. 397-415.

Pissarides, C. (2000) “Equilibrium Unemployment Theory,” MIT Press.

Schmitt-Grohe S. and Uribe M. (2004) "Solving Dynamic General Equilibrium Models Using a Second-Order Approximation to the Policy Function," Journal of Economic Dynamics and Control, Vol. 28, pp. 755-775.

Shimer R. (2005) "The Cyclical Behavior of Equilibrium Unemployment and Vacancies," The American Economic Review, Vol. 95, pp. 25-49.

Thomas C. (2008) "Search and Matching Frictions and Optimal Monetary Policy," Journal of Monetary Economics, Vol. 55, pp.936-956.

Tobin J. (1972) “Inflation and Unemployment,” The American Economic Review, Vol. 62, pp. 1-18.

Trigari A. (2006) "The Role of Search Frictions and Bargaining for Inflation Dynamics," Bocconi Univesity, Working Paper Series No. 304.

Trigari A. (2009) "Equilibrium Unemployment, Job Flows and Inflation Dynamics," Journal of Money, Credit and Banking, Vol. 41, pp.1-33.

Walsh C. (2005) "Labor Market Search, Sticky Prices and Interest Rate policies," Review of Economic Dynamics, Vol. 8, pp.829-849. 
Appendix A- Full Optimal Monetary Policy Problem: The optimal monetary policy problem is to choose $\left\{c_{t}, h_{t}, n_{t}, u_{t}, \theta_{t}, \varphi_{t}, w_{t}, \pi_{t}, \pi_{t}^{w}\right\}$ to maximize household's utility subject to the resource constraint of the economy and the equilibrium conditions of firms and individuals. Formally,

$\operatorname{Max}_{0} \sum_{t=0}^{\infty} \beta^{t}\left[\frac{c_{t}^{1-\sigma}}{1-\sigma}-n_{t} \frac{\chi}{1+\vartheta} h_{t}^{1+\vartheta}\right]$

s.t.

$\frac{\gamma}{q\left(\theta_{t}\right)}=\beta(1-\rho) E_{t}\left\{\left(\frac{u_{c t+1}}{u_{c t}}\right)\left[\varphi_{t+1} z_{t+1} f\left(h_{t+1}\right)-w_{t+1} h_{t+1}-\frac{\phi}{\psi^{2}}\left(\exp \left[-\psi\left(\pi_{t+1}^{w}-1\right)\right]+\psi\left(\pi_{t+1}^{w}-1\right)-1\right)+\frac{\gamma}{q\left(\theta_{t+1}\right)}\right]\right\}$

$\frac{\omega_{t}}{1-\omega_{t}}\left[\varphi_{t} z_{t} f\left(h_{t}\right)-w_{t} h_{t}-\frac{\phi}{\psi^{2}}\left(\exp \left[-\psi\left(\pi_{t}^{w}-1\right)\right]+\psi\left(\pi_{t}^{w}-1\right)-1\right)+\frac{\gamma}{q\left(\theta_{t}\right)}\right]=w_{t} h_{t}-\frac{v\left(h_{t}\right)}{u_{c t}}-b+E_{t}\left[\frac{\omega_{t+1}}{1-\omega_{t+1}}\left(\frac{\gamma}{q\left(\theta_{t}\right)}-\gamma \theta_{t}\right)\right]$ $\left[1-\varepsilon+\varepsilon \varphi_{t}-\phi^{p}\left(\pi_{t}-1\right) \pi_{t}\right] z_{t} n_{t} h_{t}^{\alpha}+\beta \phi^{p} E_{t}\left[\left(c_{t+1}^{-\sigma} c_{t}^{\sigma}\right)\left(\pi_{t+1}-1\right) \pi_{t+1} z_{t+1} n_{t+1} h_{t+1}^{\alpha}\right]=0$

$\frac{w_{t}}{w_{t-1}}-\frac{\pi_{t}^{w}}{\pi_{t}}=0$

$1-n_{t}-u_{t}=0$

$n_{t+1}-(1-\rho)\left(n_{t}+\sigma_{m} u_{t} \theta_{t}^{1-\zeta}\right)=0$

$n_{t} z_{t} h_{t}^{\alpha}-c_{t}-\gamma \theta_{t} u_{t}-\frac{\phi}{\psi^{2}}\left(\exp \left[-\psi\left(\pi_{t}^{w}-1\right)\right]+\psi\left(\pi_{t}^{w}-1\right)-1\right) n_{t}-\frac{\psi^{p}}{2}\left(\pi_{t}-1\right)^{2} n_{t} z_{t} h_{t}^{\alpha}=0$

$\frac{\Gamma_{t}}{1-\Gamma_{t}}\left[\varphi_{t} z_{t} f\left(h_{t}\right)-w_{t} h_{t}-\frac{\phi}{\psi^{2}}\left(\exp \left[-\psi\left(\pi_{t}^{w}-1\right)\right]+\psi\left(\pi_{t}^{w}-1\right)-1\right)+\frac{\gamma}{q\left(\theta_{t}\right)}\right]=w_{t} h_{t}-\frac{v\left(h_{t}\right)}{u_{c t}}-b+E_{t}\left[\frac{\Gamma_{t+1}}{1-\Gamma_{t+1}}\left(\frac{\gamma}{q\left(\theta_{t}\right)}-\gamma \theta_{t}\right)\right]$ 


\begin{tabular}{c|c|c|c|c|c}
\hline & I & II & III & IV & V \\
\hline Moments & $\begin{array}{c}\text { The Standard } \\
\text { Deviations of } \\
c, n \text { and } \pi^{w}\end{array}$ & $\begin{array}{c}\text { The Standard } \\
\text { Deviations of } \\
c, h, w, \pi^{w} \text { and } n\end{array}$ & $\begin{array}{c}\text { The Standard } \\
\text { Deviations of } \\
c, w, \theta\end{array}$ & $\begin{array}{c}\text { The Standard } \\
\text { Deviations of } \\
c, w, \pi^{w} \text { and } \theta\end{array}$ & $\begin{array}{c}\text { The Standard } \\
\text { Deviations of } \\
c, \pi^{w} \text { and } \theta\end{array}$ \\
\hline$\pi$ & 1.8016 & 1.8706 & 2.2324 & 2.3757 & 2.4372 \\
$\pi^{w}$ & 1.8256 & 1.8645 & 2.1971 & 2.4201 & 2.4359 \\
\hline
\end{tabular}

Table 2: Simulated moments- Second order approximation. Each entry shows the annualized mean of the variable.
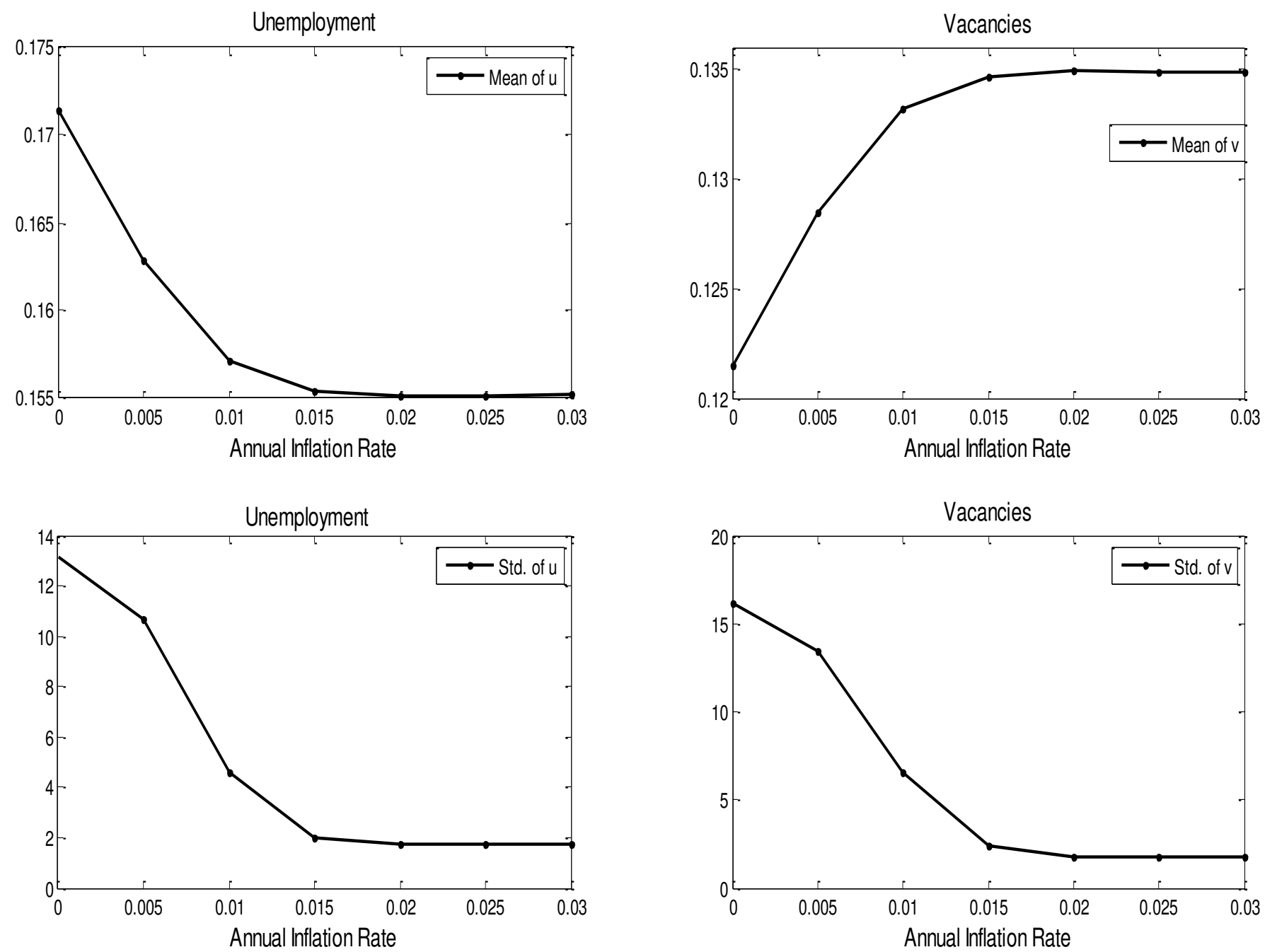

Figure 1: The mean values and standard deviations of unemployment and vacancies for various levels of annual inflation rates. 

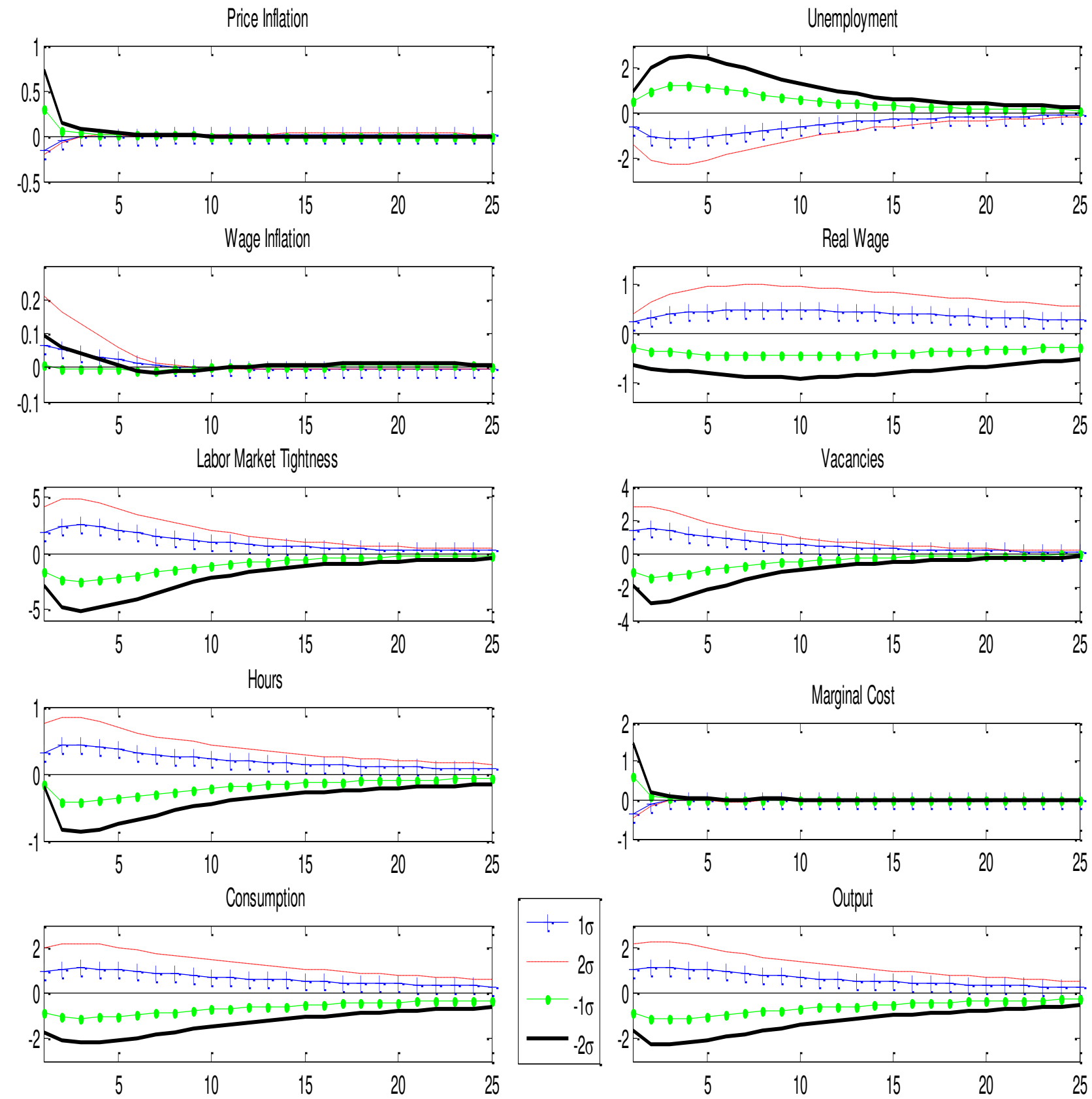

Figure 2: Response to a negative productivity shock with asymmetric wage adjustment cost function (percentage deviations from SS levels). $1 \sigma$ : a positive 1 standard deviation shock. $-1 \sigma$ : a negative 1 standard deviation shock. $2 \sigma$ : a positive 1 standard deviation shock. $-2 \sigma$ : a negative 1 standard deviation shock. 
Price Inflation
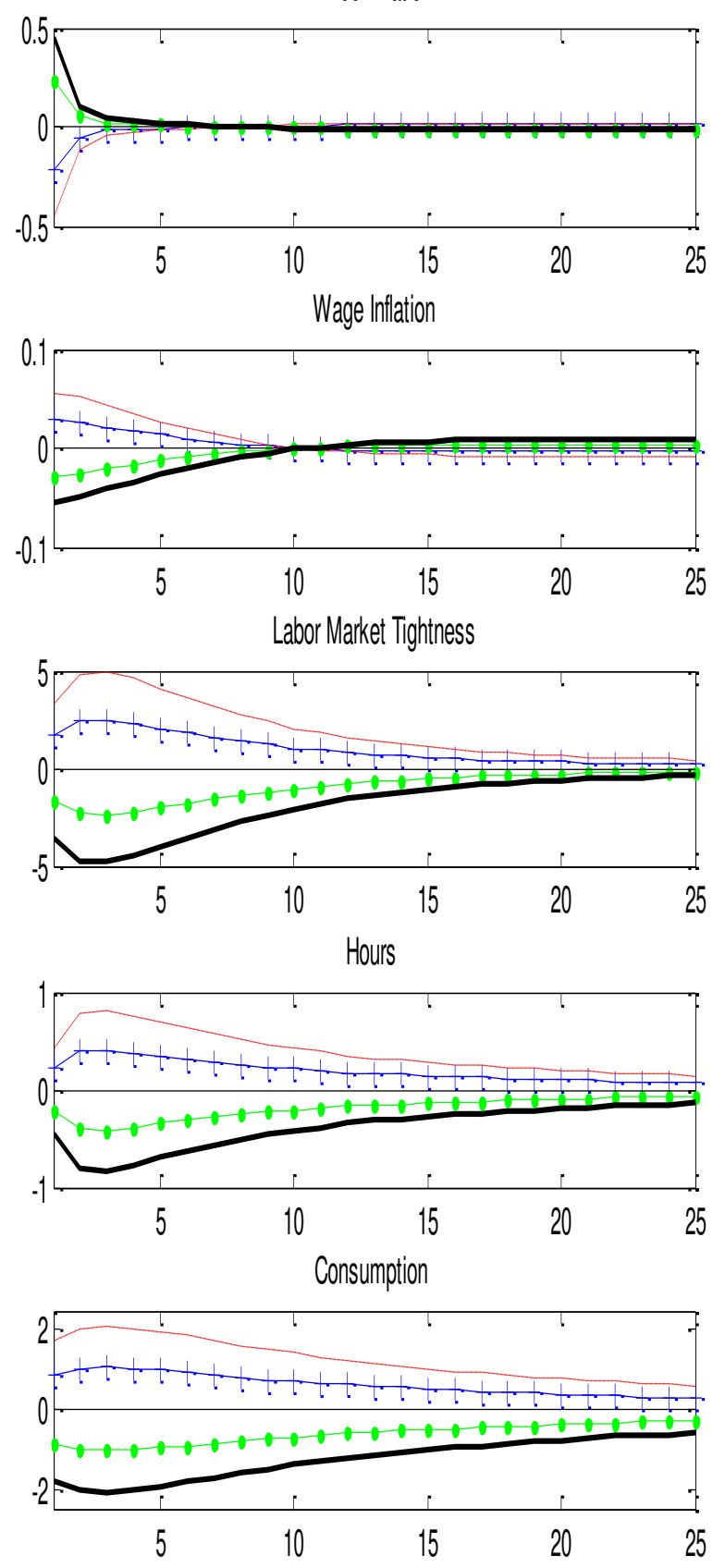

Unemployment
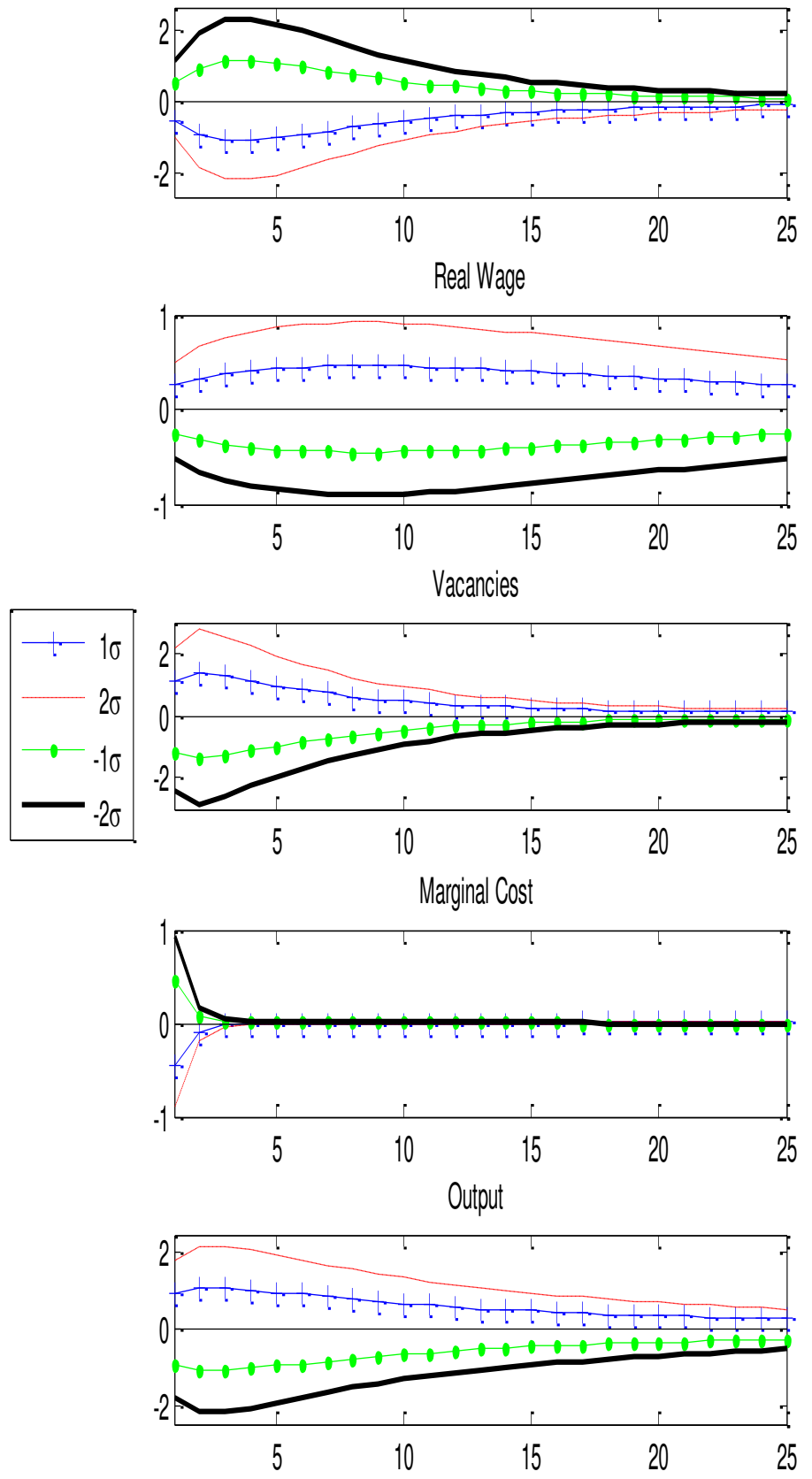

Figure 3: Response to a negative productivity shock with symmetric wage adjustment cost function (percentage deviations from SS levels). $1 \sigma$ : a positive 1 standard deviation shock. $-1 \sigma$ : a negative 1 standard deviation shock. $2 \sigma$ : a positive 1 standard deviation shock. $-2 \sigma$ : a negative 1 standard deviation shock. 
Price Inflation

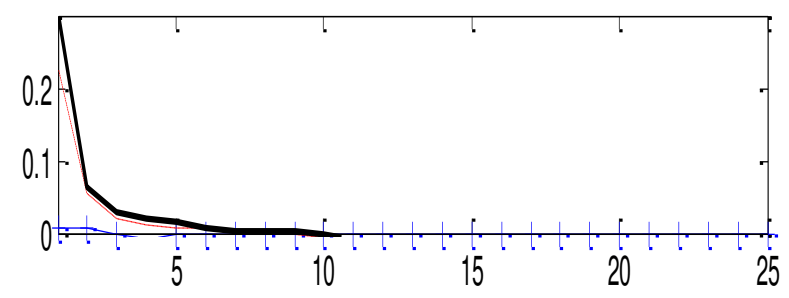

Wage Inflation

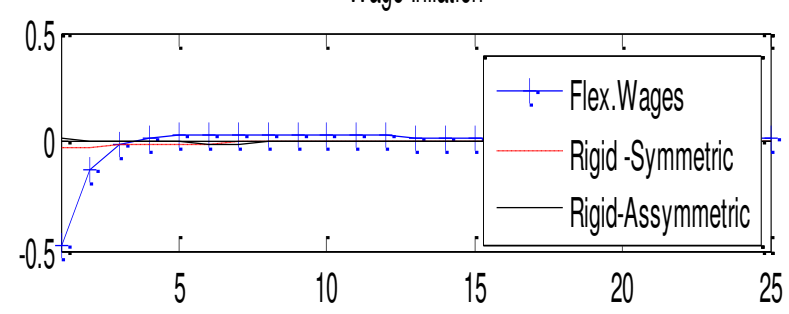

Labor Market Tightness
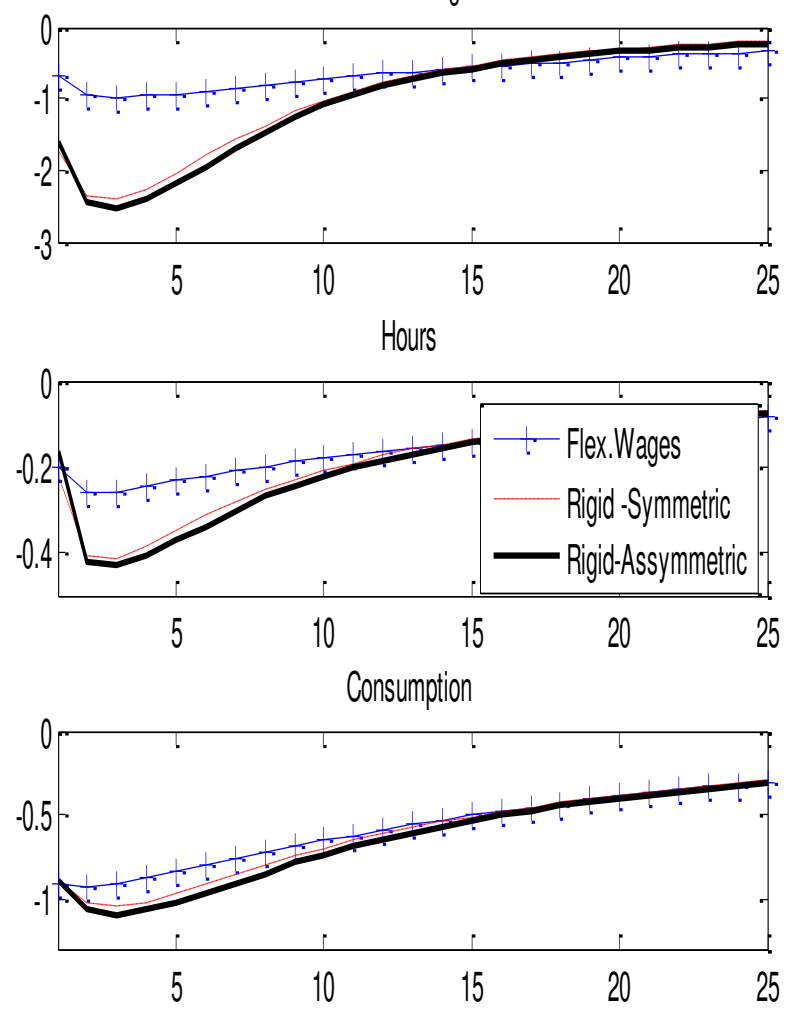

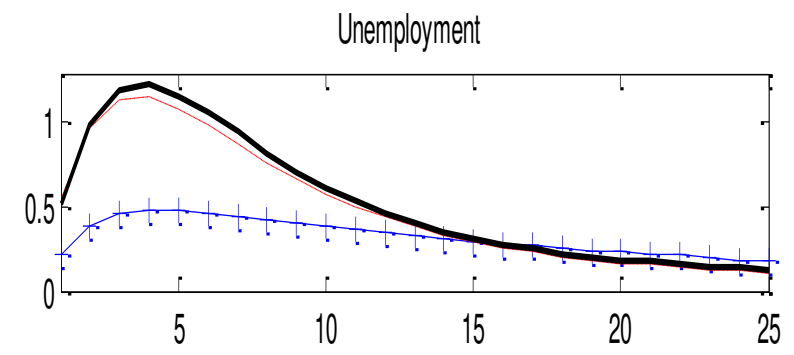

Real Wage
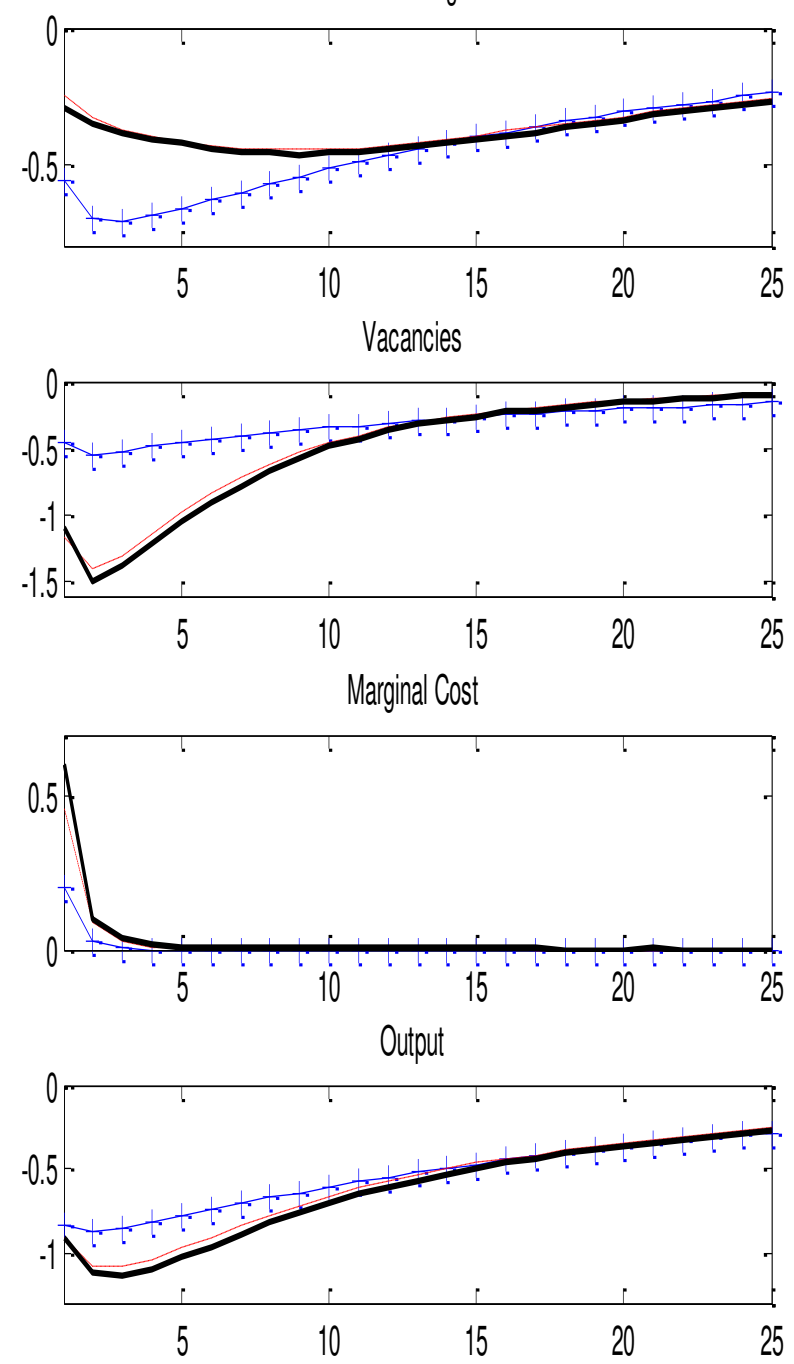

Figure 4: Response to negative productivity shocks- Flexible nominal wages, symmetric wage adjustment cost function and asymmetric wage adjustment cost function (percentage deviations from SS levels). 
Price Inflation
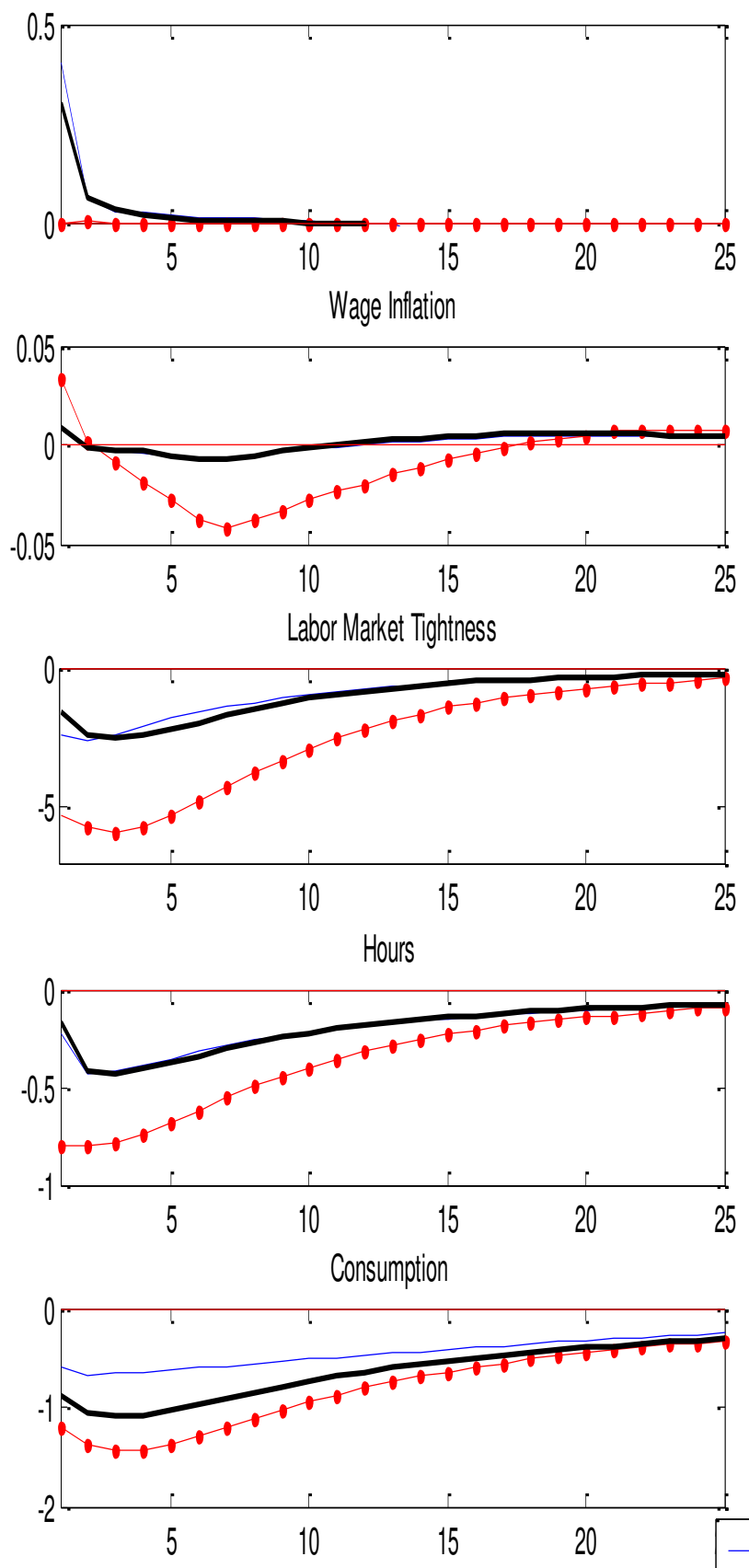

\begin{tabular}{l|lllll}
- Constant u & 5 & 10 & 15 & 20 & 25 \\
$\rightarrow-$ Constant Pl & & & & &
\end{tabular}

Figure 5: Response to negative productivity shocks with asymmetric wage adjustment cost function (percentage deviations from SS levels). 